\title{
氧化铝包覆层对甲烷燃烧反应钯催化剂活性结构的稳定作用
}

覃勇

中国科学院山西煤炭化学研究所, 煤转化国家重点实验室, 太原 030001

\section{Stabilization of Active Structures of Pd catalysts for Methane Combustion by $\mathrm{Al}_{2} \mathrm{O}_{3}$ Overlayers}

\section{QIN Yong}

State Key Laboratory of Coal Conversion, Institute of Coal Chemistry, Chinese Academy of Sciences, Taiyuan 030001, P. R. China. Email: qinyong@sxicc.ac.cn.

Published online: June 28, 2019.

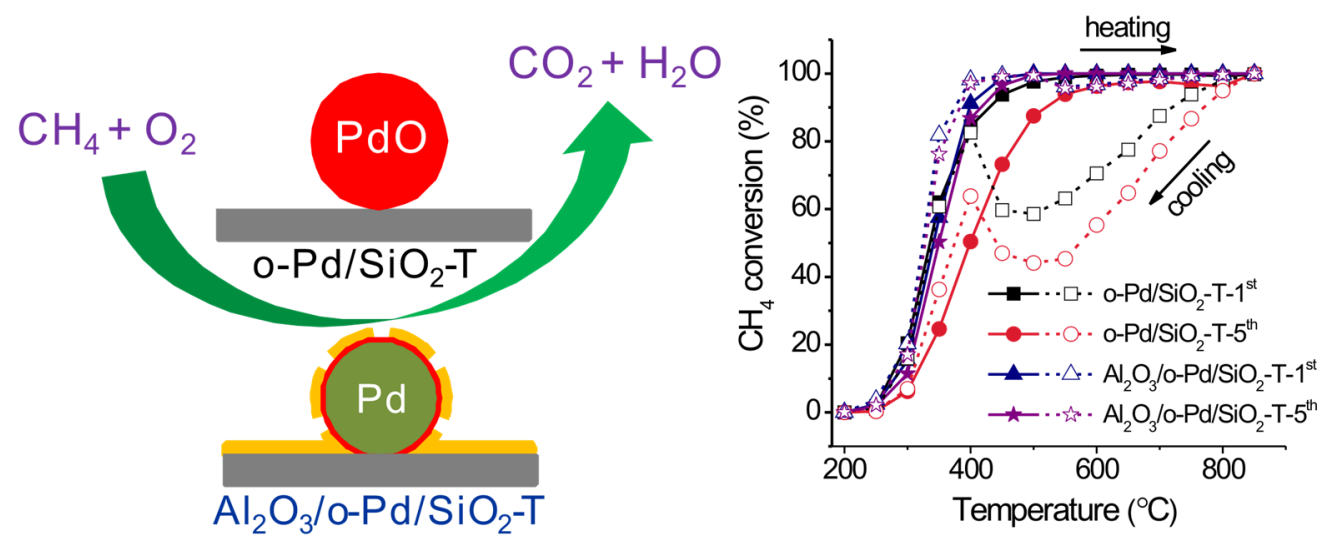

$\mathrm{Al}_{2} \mathrm{O}_{3}$ 包覆 $\left(\mathrm{Al}_{2} \mathrm{O}_{3} / \mathrm{o}-\mathrm{Pd} / \mathrm{SiO}_{2}-\mathrm{T}\right)$ 和未包覆(0-Pd/SiO $\left.2-\mathrm{T}\right)$ 催化剂结构示意图(左)及催化甲烷燃烧反应活性图(右)。

甲烷具有高的温室效应, 因此天然气应用过 程尾气中甲烷的消除是一个迫切和亟待解决的环 境问题 ${ }^{\circ}$ 。Pd基催化剂广泛应用于催化甲烷燃烧反 应, 并且表现出显著的结构敏感性 ${ }^{2}$ 。实验和理论 计算研究结果均表明 $\mathrm{Pd}-\mathrm{PdO}_{x}$ 界面表现出最高的 催化甲烷燃烧活性 3,4 。但是, 在强放热甲烷燃烧反 应氛围下, $\mathrm{PdO}_{x}$ 相易高温分解为金属 $\mathrm{Pd}$ 相, 从而 降低Pd基催化剂活性 5 。 $\mathrm{PdO}_{x}$ 相高温不稳定性在天 然气汽车的废气处理会产生严重的影响。汽车运 行过程中多变的操作环境会导致废气处理催化剂 工作温度的骤升骤降, 高温下 $\mathrm{PdO}_{x}$ 相的分解和低 温下金属Pd相较慢重新氧化会导致Pd基催化剂催 化甲烷燃烧活性的急剧衰减。因此, 维持 $\mathrm{Pd}-\mathrm{PdO}_{x}$ 活性结构的高温稳定性和提高降温过程中金属 Pd 相的重新氧化能力是甲烷燃烧 $\mathrm{Pd}$ 基催化剂研究的
热点。制备 $\mathrm{Pd} @ \mathrm{CeO}_{2}$ 核-壳结构是是一种有效的策 略6。一方面, $\mathrm{Pd} @ \mathrm{CeO}_{2}$ 核-壳结构能够抑制 $\mathrm{Pd}$ 颗粒 高温烧结; 另一方面, $\mathrm{Pd}-\mathrm{CeO}_{2}$ 界面的形成能够提 高金属Pd相催化甲烷燃烧活性。

近年来, 原子层沉积(ALD)方法被广泛应用于 在金属颗粒表面形成氧化铝包覆层来优化金属颗 粒的催化活性和抗烧结能力 7 。但是, 氧化铝包覆 层与金属颗粒之间相互作用以及对金属催化性能 优化机制的相关研究较少。

最近, 中国科学技术大学黄伟新教授课题组 在国际化学领域权威期刊Angewandte Chemie International Edition 上发表题为 $《 \mathrm{Al}_{2} \mathrm{O}_{3}$ 包覆 $\mathrm{Pd}$ 催 化剂表面五配位 $\mathrm{Al}^{3+}$ 稳定的活性Pd结构用于甲烷 催化燃烧》的文章 ${ }^{8}$, 报道了 ALD法制备的 $\mathrm{Al}_{2} \mathrm{O}_{3} / \mathrm{Pd} / \mathrm{SiO}_{2}$ 催化剂在甲烷催化燃烧反应中的高 
热稳定性, 并揭示了相关作用机制。作者通过ALD 技术在 $\mathrm{Pd} / \mathrm{SiO}_{2}$ 催化剂表面制备了约 $8 \mathrm{~nm}$ 厚的氧化 铝包覆层, 经过 $900{ }^{\circ} \mathrm{C}$ 焙烧活化后获得的 $\mathrm{Al}_{2} \mathrm{O}_{3} / \mathrm{Pd} / \mathrm{SiO}_{2}$ 催化剂在 $200-850{ }^{\circ} \mathrm{C}$ 条件下催化甲 烷燃烧反应循环升温和降温测试中表现出高活性 和高稳定性。不同探测深度XRD、XPS和DRIFT结 构表征结果和 TPO 循环测试结果表明 $\mathrm{Al}_{2} \mathrm{O}_{3} / \mathrm{Pd} / \mathrm{SiO}_{2}$ 催化剂表面具有稳定的 $\mathrm{PdO}_{x}$ 相, 在 甲烷燃烧反应中发生 $\mathrm{Pd} @\left(\right.$ dominant $\mathrm{PdO}_{x}+$ minor $\mathrm{Pd}) \leftrightarrow \mathrm{Pd}(0)$ 的可逆变化, 而未包覆 $\mathrm{Pd} / \mathrm{SiO}_{2}$ 催化剂 发生 $\mathrm{PdO} \leftrightarrow \mathrm{PdO} @ \mathrm{Pd}(0)$ 的可逆变化。 ${ }^{27} \mathrm{Al}$ 魔角旋转 固体核磁表征结果观察到ALD方法沉积的氧化铝 具有大量五配位 $\mathrm{Al}^{3+}$ 位点的存在, 在焙烧活化过程 中, 五配位 $\mathrm{Al}^{3+}$ 位点与表面临近的 $\mathrm{PdO}_{\mathrm{x}}$ 相发生强相 互作用, 从而稳定了 $\mathrm{PdO}_{x}$ 相。因此, $\mathrm{Al}_{2} \mathrm{O}_{3} / \mathrm{Pd} / \mathrm{SiO}_{2}$ 催化剂具有稳定高效的 $\mathrm{PdO}_{x}$ 和Pd-PdO 活性结构。

此项研究工作揭示了ALD方法制备氧化铝包 覆层具有大量五配位 $\mathrm{Al}^{3+}$ 位点的结构特征, 氧化铝 包覆层不仅能够提高包覆Pd颗粒的抗烧结性能, 而 且能够通过五配位 $\mathrm{Al}^{3+}$ 位点-Pd活性结构强相互作 用来稳定Pd活性结构, 对甲烷燃烧反应以及其它 高热反应高效稳定Pd基催化剂的结构设计具有重 要的指导和借鉴意义。此项研究工作得到了科技 部国家重点研发计划、国家自然科学基金委、中科
院、教育部长江学者奖励计划等项目的经费支持。

\section{References}

(1) Cargnello, M.; Jaen, J. J. D.; Garrido, J. C. H.; Bakhmutsky, K.; Montini, T.; Gamez, J. J. C.; Gorte, R. J.; Fornasiero, P. Science 2012, 337, 713. doi: 10.1126/science. 1222887

(2) Murata, K.; Mahara, Y.; Ohyama, J.; Yamamoto, Y.; Arai, S.; Satsuma, A. Angew. Chem. Int. Ed. 2017, 56, 15993. doi: 10.1002/anie.201709124

(3) Kinnunen, N. M.; Hirvi, J. T.; Venäläinen, T.; Suvanto, M.; Pakkanen, T. A. Appl. Catal. A: Gen. 2011, 397, 54. doi: 10.1016/j.apcata.2011.02.013

(4) Kinnunen, N. M.; Hirvi, J. T.; Suvanto, M.; Pakkanen, T. A. J. Phys. Chem. C 2011, 115, 19197. doi: 10.1021/jp204360c

(5) Xiong, H. F.; Lester, K.; Ressler, T.; Schlögl, R.; Allard, L. F.; Datye, A. K. Catal. Lett. 2017, 147, 1095. doi: 10.1007/s10562-017-2023-7

(6) Feng, X. L.; Li, W.; Liu, D. P.; Zhang, Z.; Duan, Y.; Zhang, Y. Small 2017, 13, 1700941. doi: 10.1002/smll.201700941

(7) Lu, J. L.; Fu, B. S.; Kung, M. C.; Xiao, G. M.; Elam, J. W.; Kung, H. H.; Stair, P. C. Science 2012, 335, 1205. doi: $10.1126 /$ science. 1212906

(8) Duan, H. M.; You, R.; Xu, S. T.; Li, Z. R.; Qian, K.; Cao, T.; Huang, W. X.; Bao, X. H. Angew. Chem. Int. Ed. 2019, 58, 12043. doi: 10.1002/anie.201904883 